\title{
Vendo e Ouvindo Vozes - A Caminho da Educomunicação
}

\author{
Maria Cristina Castilho Costa* \\ Departamento de Comunicações e Artes \\ Escola de Comunicações e Artes da Universidade de São Paulo
}

\section{GradP \\ Revista de Graduação USP}

\author{
* Autor para correspondência: criscast@usp.br
}

\section{RESUMO}

O presente trabalho mostra como os textos escritos pelo neurologista Oliver Sacks, especialmente em seu livro Vendo Vozes, podem ser usados na formação do educomunicador. Tal profissional atua em atividades educativas, formais ou informais, públicas ou privadas, e nos meios de comunicação. Para desempenhar de modo satisfatório suas atribuições, faz-se necessário que ele tenha uma visão interdisciplinar sobre o mundo e desenvolva uma atitude crítica e democrática em relação à sociedade em que vive. Entendemos que unindo teoria à prática, o conhecimento a uma atitude participativa, a produção cultural e artística se mostra como um meio privilegiado para o exercício da educomunicação.

Palavras-chave: Educomunicação; Arte; Comunicação; Educação; Linguagem.

\begin{abstract}
The present paper demonstrates how the writings of Oliver Sacks, especially the work Seeing Voices, can be used in the shaping of the Educommunicators. These professionals are present in formal and informal, public and private educational activities and in the media. To perform their duties satisfactorily, it is necessary that they offer an interdisciplinary perspective on society and help to develop a critical and democratic attitude. Combining theory and practice, knowledge and a participatory attitude, the cultural and artistic production is the privileged media for educommunication.
\end{abstract}

Keywords: Educommunication; Art; Communication; Education; Language.

\section{Arte e Sociedade}

Fui artista plástica desde a adolescência, tendo sido desenhista, pintora, gravadora, escultora, enquanto completava a minha graduação em Ciências Sociais. Quando, enfim, comecei a dar aulas e me encaminhei para as lides acadêmicas, ingressando na pós-graduação, aos poucos fui abandonando a produção artística, mas nunca o aprendizado sobre a importância da arte como expressão particular do artista e coletiva da sociedade. Tendo vivenciado a forma espontânea, direta e crítica com que a arte expressa a realidade social, dediquei-me, na pós-graduação, a entender a sociedade através de suas manifestações artísticas ${ }^{1}$. Meu mestrado e doutorado analisaram a pintura brasileira dos séculos XVIII, XIX e XX, buscando os valo- res, os costumes, as expectativas da sociedade brasileira $^{2}$. Foi com essa bagagem que ingressei na Escola de Comunicações e Artes, passando então a estudar as mídias e a produção simbólica da sociedade. Minha livre-docência ${ }^{3}$ estudou o gancho das telenovelas, procurando entender como essa forma narrativa criava o hábito de recepção diária nos telespectadores.

Toda essa vivência como pesquisadora da arte e da produção simbólica envolvia a leitura muito seletiva de diversos autores que tinham trabalhado com as relações complexas entre cultura e representação, entre autores e público, entre personalidades e convenções. Desses autores devemos destacar Umberto Eco que, em seu livro Obra Aberta, mostrou como uma obra pode oferecer espaço para interpretações 
e como o artista pode atuar como agente catalisador das tendências artísticas, culturais e ideológicas de seu tempo. O mesmo autor escreveu também Seis Passeios pelos Bosques da Ficção, no qual disserta sobre as formas narrativas e sobre como elas induzem o leitor, o espectador e o público em geral a se envolverem na ficção. O historiador da arte E. H. Gombrich, em sua obra-mestra Arte e Ilusão, mostrou os aspectos convencionais das formas de representação e como estas expressam uma visão de mundo arquitetada pela cultura em determinado tempo e lugar. Gaston Bachelard, em A Poética do Espaço, estabelece importante relação entre a percepção e a vida cotidiana, perpassada por nossa sensibilidade, memórias e afetividade. Michael Baxandall, em sua análise da arte renascentista presente em O Olhar Nascente, mostrou como a preocupação economicista do capitalismo emergente se expressou na constituição de um espaço pictórico milimetrado e matemático, que deu origem à representação perspectiva. A razão simbólica da perspectiva plana, que caracterizou a arte visual do ocidente pós-renascentista, foi também estudada por Erwin Panofski, em $A$ Perspectiva como Forma Simbólica.

No campo da chamada Sociologia da Arte uma especialização das Ciências Sociais - também havia diversos autores importantes, como Roger Bastide, que passou uma década no Brasil estudando as relações entre arte, cultura e sociedade. Philippe Ariés, por sua vez, reconstituiu a história da infância a partir da análise dos retratos de crianças. Não podemos deixar de lembrar de Pierre Bourdieu, que estudou a formação do campo artístico em sua obra As Regras da Arte. Néstor García Canclini, sociólogo mexicano, pesquisou as formas de apropriação do fazer artístico pela sociedade em A Socialização da Arte. Por fim, Arnold Hauser, em The Sociology of Art, elaborou uma história da arte a partir da história da sociedade ocidental. No Brasil, inúmeros autores contribuíram para essa perspectiva sociológica da produção artística, desde Mário de Andrade, Gilda de Mello e Souza, Antonio Candido a Alexandre Eulálio.
Com essa bagagem teórico-metodológica, dediquei-me ao estudo da produção simbólica. Com essa bagagem, organizei as disciplinas de graduação que passei a ministrar, desde 1996, na Escola de Comunicações e Artes da USP.

\section{Interpretação Fenomenológica}

Se, do ponto de vista teórico, foi desses autores que me servi, numa proposta nitidamente interdisciplinar, envolvendo sociólogos, antropólogos, historiadores, críticos de arte, linguistas, do ponto de vista empírico, amparei-me em metodologia empregada por diversos deles, que denomino de interpretação fenomenológica. Também conhecida por hermenêutica, a ciência da decifração de textos, essa metodologia parte não de uma organização dedutiva de premissas teóricas, mas de um amplo levantamento (ou mapeamento) de ocorrências empíricas. Além dessa postura indutiva, a fenomenologia parte do princípio de que um texto está intimamente relacionado não com a realidade, mas com a intencionalidade do autor. Assim, é a subjetividade deste que o texto revela, por meio de um intenso trabalho de desconstrução interpretativa dos signos e linguagens. Por outro lado, essa subjetividade do autor revela indiretamente as visões de mundo que se contrapõem em um tempo/espaço determinado sociologicamente, levando-nos, como nos bosques da ficção apresentados por Eco, à realidade percebida e elaborada por ele. A interpretação do texto, nessa perspectiva, exige a compreensão da linguagem, das tecnologias, dos signos e da relação sígnica que se processa entre o autor e a realidade circundante sobre a qual se expressa.

A construção dessa metodologia, bem como de sua justificação teórica, exigiu a consulta de outra série de autores, a começar pelos filósofos Edmond Hüsserl, Maurice Merleau-Ponty, Mikel Dufrenne, Ernest Cassirer e, principalmente, Jean-Paul Sartre, em suas obras A Imaginação e O Imaginário. Outros autores ajudaram na compreensão da relação entre cognição, realidade e expressão estética, artística e ficcional. Entre eles colocamos Steven Pinker e Claude Lévy-Strauss. 
Pois bem, foi a partir da construção de um aparato teórico-metodológico que estabelecesse as ligações entre realidade social, linguagem e subjetividade que entrei em contato com Oliver Saks, de quem passo a falar agora.

\section{Oliver Sacks e sua Obra Vendo Vozes}

Oliver Sacks nasceu na Inglaterra, em 1933, em uma família de intelectuais e cientistas judeus. Desde pequeno, interessou-se por ciências e tornou-se um químico amador. Graduou-se em medicina, fisiologia e biologia pela Universidade de Oxford. Passou a viver nos Estados Unidos desde 1965, onde trabalhou e lecionou em diversas universidades, dedicando-se à neurologia e à psiquiatria. Era interessado no estudo da mente humana, mas o que caracterizou suas pesquisas e as obras que escreveu era o caráter humanista e antropológico de suas abordagens. Ele não estava apenas preocupado com o funcionamento do cérebro, mas, principalmente, em como esse funcionamento estava ligado a uma sensibilidade, a uma história de vida, a uma personalidade e a um momento histórico. Sacks escreveu inúmeros livros, alguns baseados em sua experiência pessoal de vida e outros em relatos de pacientes cujos transtornos neurológicos ele acompanhou. São livros de leitura fácil, produzidos por um autor que buscava divulgar a ciência para um grande público. Alguns textos acabaram sendo adaptados para o cinema com sucesso, como À Primeira $V i s t a^{4}$, inspirado no capítulo "Ver ou Não Ver", de seu livro Um Antropólogo em Marte. Tempo de Despertar ${ }^{5}$ também foi baseado em texto biográfico escrito pelo cientista, no qual narra sua experiência com doentes portadores de encefalite letárgica, aos quais ministrou uma droga controversa que os tirava de seu estado catatônico.

A leitura de artigos e textos de Oliver Sacks veio a criar a ligação que faltava entre os autores da base teórica que expus neste relato, permitindo entender a linguagem e a comunicação em seus aspectos biológicos e fisiológicos, e não apenas culturais e linguísticos. Assim, Sacks passou a fazer parte integrante da bibliografia das disci- plinas que ministrei na Escola de Comunicações e Artes, especialmente na Licenciatura em Educomunicação. Utilizo seus textos, sempre de fácil comunicação e compreensão, para discussões a respeito da percepção, dos processos mentais, da comunicação e da cultura. Dentre eles, destaco um livro primoroso intitulado Vendo Vozes.

Nessa obra, o autor dedica-se ao estudo da linguagem dos sinais. Começa por narrar como era a vida dos surdos-mudos antes da criação e divulgação da língua dos sinais: tratados como portadores de dificuldades mentais, quando seus problemas derivavam de não poderem se expressar e de não entenderem o que os outros diziam, condição que os tornava excluídos da cultura e do conhecimento. Depois, analisa a língua dos sinais, mostrando que ela não é uma mera gesticulação, mas um recurso linguístico complexo e importante que possibilita expressões sutis como a ficção e a poesia. Finalmente, discute a forma como os surdos-mudos, podendo se comunicar uns com os outros, acabaram por elaborar uma cultura peculiar e tomar consciência de suas próprias necessidades e anseios. Trata-se de um excelente texto, que permite ao leitor entender a relação entre percepção, pensamento, linguagem e cultura, base dos pressupostos teórico-metodológicos com os quais trabalho.

As atividades pedagógicas que o trabalho com esse texto tem possibilitado são muito fecundas. Os alunos, sempre divididos em grupos, apresentam seminários nos quais debatem as principais ideias expostas por Sacks e apresentam pesquisa própria inspirada por elas. São depoimentos pessoais, entrevistas, apresentação de vídeos, interpretações teatrais que exploram as questões culturais e linguísticas assim como as políticas presentes na obra - a necessidade de dar voz a minorias excluídas da cultura hegemônica. Com esses trabalhos, um dos quais apresentado no $1^{\circ}$ Congresso de Graduação da USP, torna-se possível, além do aprendizado e da aplicação dos conceitos aprendidos, posicionar-se de forma crítica e cidadã diante da sociedade. Dessa maneira, alcançamos os resultados que nós, professores da Licenciatura de Educomunicação da ECA-USP, almejamos para nossos alunos. 


\section{Educomunicador}

A Educomunicação é uma área do conhecimento que se desenvolveu na interface entre as Ciências da Comunicação e a Educação, e pretende formar profissionais capazes de agir em atividades pedagógicas e educativas utilizando os recursos comunicacionais, os meios de comunicação e suas linguagens. Seus profissionais são capazes também de atuar junto a um público crítico e consciente, podendo interagir com essa sociedade midiática que se avoluma ao nosso redor. Ele é competente, ainda, para atuar profissionalmente nos veículos de comunicação de forma participativa e democrática, dando voz a setores, grupos e classes com pouco espaço de interlocução. Para atingir esses objetivos, o curso de Licenciatura em Educomunicação oferece sólida base teórica de caráter humanista, profundo conhecimento dos meios de comunicação e suas linguagens, além de formação política e sociológica que permite entender o tempo e o país nos quais o profissional deverá atuar. Toda essa programação se apresenta através de atividades teórico-práticas que permeiam a formação do educomunicador, tornando-o apto a atuar na educação formal e informal, em instituições públicas e privadas, nos meios de comunicação e em atividades ligadas à responsabilidade social e ao chamado terceiro setor.

Para isso, os estudos das linguagens mediáticas, assim como da produção simbólica cultural e artística, é de enorme importância, na medida em que é nesse campo, onde melhor se combinam sensibilidade, percepção, linguagem e reflexão, que se torna possível a vivência dos princípios teóricos que se quer aprendidos. A arte, rompendo com os esquemas lógico-racionais, com o pragmatismo que por vezes obscurece a ciência, permite um novo desvendar do mundo e da sociedade, novas formas de interlocução e inéditas maneiras de compreender o eu e o outro.

Vendo Vozes permite isso na medida em que, colocando em um balão de ensaio a comunidade surda, ensina a importância da linguagem, do diálogo e da posição política na realização integral do ser humano. Assim, através de um caso particular - o da comunidade surda -, o aluno tem acesso a uma experiência concreta sobre a realização humana, sobre a possibilidade de existência de uma sociedade saudável e minimamente democrática.

\section{Conclusão}

As disciplinas que ministro na graduação da ECA-USP são obrigatórias para a licenciatura em Educomunicação ${ }^{6}$ e optativas para alunos dos demais cursos da unidade e para graduandos externos à escola. Não é difícil ter grupos de alunos provenientes da área de ciências exatas e biológicas, além dos já esperados estudantes das ciências sociais. Todos se mostram muito interessados e revelam o desejo de buscar, em outras áreas do conhecimento, elementos importantes que os ajudem nas atividades profissionais didáticas que já exercem ou que pretendem exercer. Trazem para a sala de aula suas dúvidas sobre o quê e como ensinar, como fazer frente aos desafios da atualidade, em um mundo globalizado e permeado pelos meios de comunicação. Querem saber como selecionar conteúdos, como provocar interesse nos educandos, como se aproximar dos mais jovens e como tornar o aprendizado mais condizente com uma sociedade em profunda mudança. As questões que levantamos com os autores aqui arrolados, a importância que damos à produção simbólica, especialmente aos processos de expressão artística, parecem estar sendo úteis para ajudar a elucidar essas grandes dúvidas. Isso mostra que o conhecimento deve ser sempre importante do ponto de vista humano, social e político, abrindo espaço para o autoconhecimento e para o conhecimento do outro, utilizando-se, para isso, não só da análise lógica, mas também da sensibilidade, da percepção e da cultura. Assim, o conhecimento permitirá ouvir e ver vozes.

\section{Notas}

1. Em meu percurso na pós-graduação, fui orientada pelo Prof. Dr. Ruy Galvão de Andrada Coelho e pela Prof ${ }^{a}$. Dr ${ }^{\mathrm{a}}$. Liana Maria Sálvia Trindade, am- 
bos do então Centro de Estudos de Sociologia da Arte, que funcionava na Faculdade de Filosofia, Letras e Ciências Humanas da USP.

2. Meu mestrado intitulou-se "O Retrato Feminino na Pintura Brasileira - Do Realismo ao Romantismo. Análise Estética e Sociológica" e foi apresentado, em 1985, à Faculdade de Filosofia, Letras e Ciências Humanas da Universidade de São Paulo (FFLGH-USP). Meu doutorado intitulou-se "A Pintura do Barroco Mineiro das Cidades do Ciclo do Ouro - Mitos e História", apresentado, em 1990, à FFLCH-USP.

3. Minha tese de livre-docência intitulou-se "O Gancho da Telenovela - Análise Estética e Sociológica”, apresentada em 1997, à Escola de Comunicações e Artes da Universidade de São Paulo (ECA/USP).

4. À PRIMEIRA Vista. Direção de Inwin Winkler. EUA, 1999.

5. TEMPO de Despertar. Direção de Penny Marshall. EUA, 1990.

6. As disciplinas ministradas são: Mídia e Sociedade, no primeiro semestre e Mídias, Arte e Educação, no segundo semestre.

\section{Referências Bibliográficas}

BACHELARD, Gaston. A Poética do Espaço. São Paulo: Martins Fontes, 1988.
BAXANDALL, Michael. O Olhar Renascente: Pintura e Experiência Social na Itália da Renascença. Rio de Janeiro: Paz e Terra, 1991.

BOURDIEU, Pierre. As Regras da Arte: Gênese e Estrutura do Campo Literário. Sao Paulo: Companhia das Letras, 1996.

CANCLINI, Néstor García. A Socialização da Arte: Teoria e Prática na América Latina. São Paulo: Cultrix, 1980.

ECO, Umberto. Obra Aberta: Forma e Indeterminacão nas Práticas Contemporâneas. $8^{a}$ ed. São Paulo: Perspectiva, 1991. Seis Passeios pelo Bosque da Ficção. São Paulo: Cia. das Letras, 1994.

HAUSER, Arnold. The Sociology of Art. Chicago: The University of Chicago Press, 1982.

PANOFSKY, Erwin. La Perspectiva como Forma Simbolica. Barcelona: Tusquets, 1980.

SACKS, Oliver W. Um Antropólogo em Marte. São Paulo: Cia. das Letras, 1995. Vendo Vozes: uma Viagem ao Mundo dos Surdos. São Paulo: Cia. das Letras, 1998.

SARTRE, Jean-Paul. A Imaginação. $8^{\mathrm{a}}$ ed. Rio de Janeiro: Editora Bertrand Brasil, 1989.

O Imaginário: Psicologia Fenomenológica da Imaginação. São Paulo: Ática, 1996.

Publicado em 05/07/2016. 
